\title{
A STUDY ON NUTRIENT FORAMEN OF HUMERI AND ITS CLINICAL
} SIGNIFICANCE

Ruthwik B S ${ }^{1}$, Padmalatha K ${ }^{*}$, Shyam Sunder B V ${ }^{3}$.

${ }^{1}$ Final year MBBS Student, ESIC Medical College \& PGIMSR, Rajajinagar, Bengaluru, Karnataka, India.

${ }^{* 2}$ Associate Professor, Department of Anatomy,ESIC Medical College \& PGIMSR, Rajajinagar, Bengaluru, Karnataka, India.

${ }^{3}$ Intern, ESIC Medical College \& PGIMSR, Rajajinagar, Bengaluru, Karnataka, India.

\section{ABSTRACT}

Background: A Nutrient Foramen [NF] or vascular channel is a small tunnel in cortex of long bones which is a pathway for the entry of nutrient artery. Nutrient artery has pivotal contribution of blood supply to long bones and plays a major role in Orthopaedic Surgical procedures like bone transplantation, bone grafting thus avoiding avascular necrosis of fractured bones

Aims: To determine morphological parameters (variation in number, location, direction) and morphometric parameters (variation in size and foraminal index [FI] ) of nutrient foramina in Humeri.

Materials and methods: Present study was conducted on a total of 80 dried human adult Humeri of either sexes or sides which were obtained from fellow students and Department of Anatomy of ESIC medical college \& PGIMSR, Bangalore. Infantometer was used to calculate length of humeri, hand held lens was used to detect nutrient foramen under adequate illumination. Hypodermic needles [ $18 \mathrm{G}$ to $26 \mathrm{G}$, where $\mathrm{G}$ is gauge], were used to measure the size of NF. Foraminal index was also calculated.

Results: In our study mean length of humerus was $29.95 \mathrm{~cm}$.FI ranged from $39.34-81.02$.Majority $(62.50 \%)$ of humeri have one NF, $(28.75 \%)$ have two NF, (7.5\%) with three nutrient foramina and $(1.25 \%)$ had no NF. Majority of NF (43.43\%) were present on antero-medial surface, $(37.37 \%)$ on medial border, $(14.14 \%)$ on posterior surface, (2.02\%) on both anterolateral surface and anterior border, $1.01 \%$ in lateral border. $(90.09 \%)$ of NF were located in Zone II (middle third), (8.08\%) in Zone III (lower third) and (1.01\%) in zone I (Upper third). Majority (41.41\%) were of large gauge, $(34.34 \%)$ of medium gauge and $(24.24 \%)$ of small gauge. All NF directed towards distal end of humerus.

Conclusion: For healing of fractures, blood supply plays a vital role. Awareness about variations in NF is important because damage to nutrient artery due to any cause like trauma, road traffic accidents will cause inadequate blood supply. Thus vascular and bone transplant surgeons can reconstruct damaged artery and avoid ischemia of graft during open reduction procedures and transplant surgeries.

KEY WORDS: Nutrient foramen, Nutrient artery, Humerus, Diaphysis.

Address for Correspondence: Dr Padmalatha K, Associate Professor, Department of Anatomy, ESIC Medical College \& PGIMSR, Rajajinagar, Bengaluru, Karnataka, India.

E-Mail: padduanat@gmail.com

Access this Article online

Quick Response code

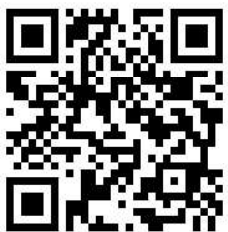

DOI: $10.16965 /$ ijar.2019.220

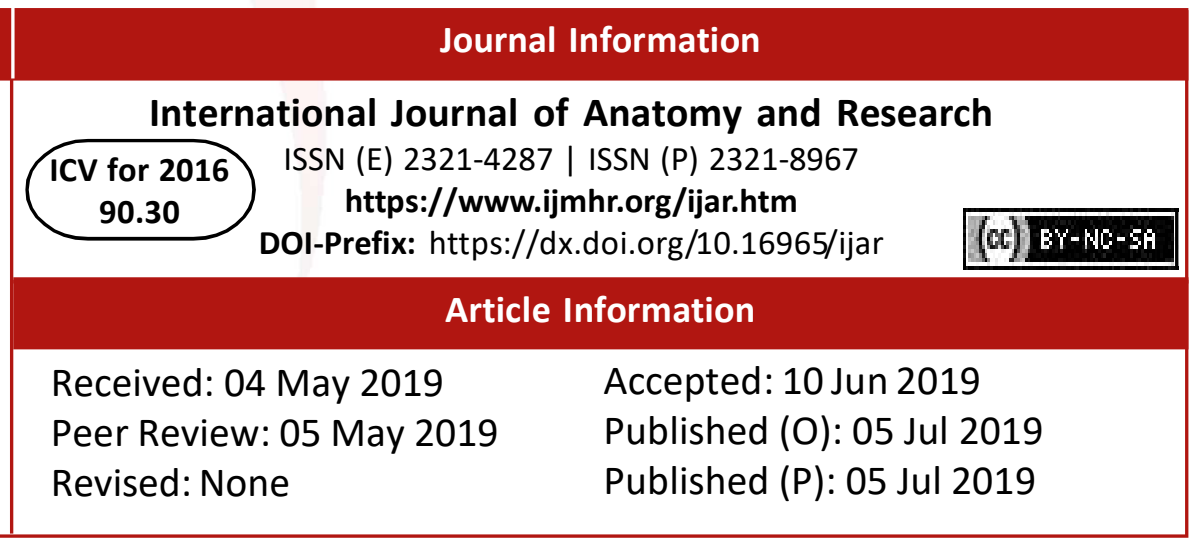

tissue which performs numerous vital functions in the human body. The blood supply to the 
bones varies according to the shape of the bone. In long bones, there are generally three sets of vessels: diaphyseal, metaphyseal and epiphyseal arteries. Diaphyseal nutrient artery is the major source of blood supply to long bones (principal source of blood supply), especially during its growth period and early stages of ossification $[1,2]$.

Nutrient foramen is an opening in the bone shaft which gives passage to the blood vessels of medullary cavity of a bone for its nourishment and growth [3]. Nutrient foramen precedes nutrient canal which is a pathway for vessels to enter and exit marrow cavity. Their sites of entry and direction are almost constant and characteristically directed away from the dominant growing ends [4]. Nutrient foramen are directed towards elbow in upper limb (directed towards lower end of humerus and upper ends of radius and ulna), while in lower limb nutrient foramen is directed away from knee (that is, upper end for femur and lower ends of tibia and fibula). This is said to be due to one end of limb bones growing faster than the other and generally follows the rule, "to the elbow I go, from knee I flee" [5-7]. Before entering the nutrient foramen, nutrient vessels become tortuous so as to not affect the bone movement [8]. Nutrient artery after entering shaft through the nutrient foramina obliquely, divides into ascending and descending branches in medullary cavity. Each branch divides into a number of small parallel channels that are terminated in adult metaphysis by anastomosing with epiphyseal, metaphyseal and periosteal arteries [9]. Position of nutrient foramina in mammalian bones are inconsistent and may alter during its growth [10]. In humans although number, position and direction are variable, usually nutrient foramina are commonly present slightly below the midpoint of the anteromedial surface (AMS) close to the medial border (MB) and is directed downwards $[4,11]$.

In this era due to industrialization, life style modification and increased dependency over machines, injury and fracture of bones are common. For the healing of wound and fractures blood supply plays a pivotal role [12,13]. Awareness about variations in number, location , size and direction of nutrient foramina is important because damage to nutrient artery due to any cause like trauma, road traffic accidents, stripping of bone surface by Orthopaedicians for plate insertion in open reduction internal fixation of comminuted fractures of shaft of humerus etc... will cause inadequate blood supply. It is a well-known fact that one of the causes of delayed union /nonunion of fracture is cutoff of arterial supply due to nutrient artery damage [14]. It also helps the vascular surgeons and bone transplant surgeons to reconstruct nutrient artery thus avoiding ischemia of the graft during arm transplant surgeries in unfortunate accident victims thus providing adequate vascularity and increasing the chances of successful transplantation.

\section{MATERIALS AND METHODS}

Present study is conducted on a total of 80 dried adult humeri (42 right sided and 32 left sided) of either sexes obtained from first year MBBS students and the Department of Anatomy at ESIC medical college\& PGIMSR, Rajajinagar, Bangalore during period of $5^{\text {th }}$ may 2018 to $11^{\text {th }}$ august 2018.Grossly deformed or fractured humeri were excluded from the study.

In each humerus, side determination was done, length was measured by using Infantometer, hand held lens was used to detect nutrient foramina under adequate light. Nutrient foramina were confirmed by using hypodermic needles of sizes ranging from (18G - 26G).Same needles were used to determine size of foramina [15]. Location of foramina were determined based on the anatomical borders and surfaces. Any foramen lying within $1 \mathrm{~mm}$ from any border was taken as lying on that border [6]. Vertical position of nutrient foramina was calculated using foraminal index(FI) using Hughes formula, $F I=(D N F \backslash T L) \times 100$ where DNF stands for distance from the proximal end of the bone to the nutrient foramen and TL stands for total length of the bone in millimeter [16]. (Figure 1 and 2).

The position of foramina was divided into three types according to $\mathrm{Fl}$ as follows:

Zone I: $\mathrm{FI}$ up to $33.33 \%$, the foramen was in proximal third of the bone.

Zone II: FI from $33.33 \%$ to $66.66 \%$, the foramen was in the middle third of bone. 
Zone III: FI above $66.66 \%$, the foramen was in the distal third of bone [17]. (Figure 3)

Fig. 1: A Photograph of Infantometer which is being used to measure the length of Humerus and foraminal index of nutrient foramen.

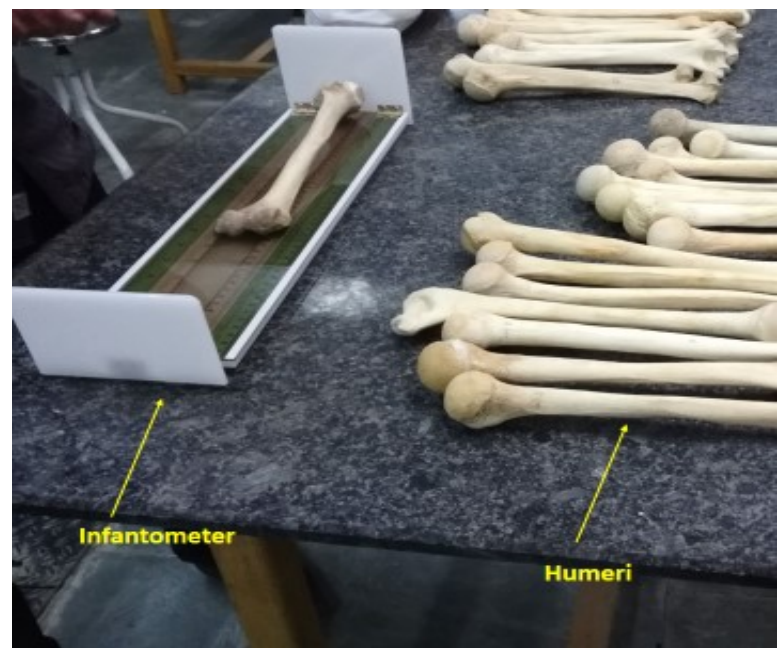

Fig. 2: Photograph showing the needles of different gauge which were used for confirmation and measurement of size of nutrient foramina.

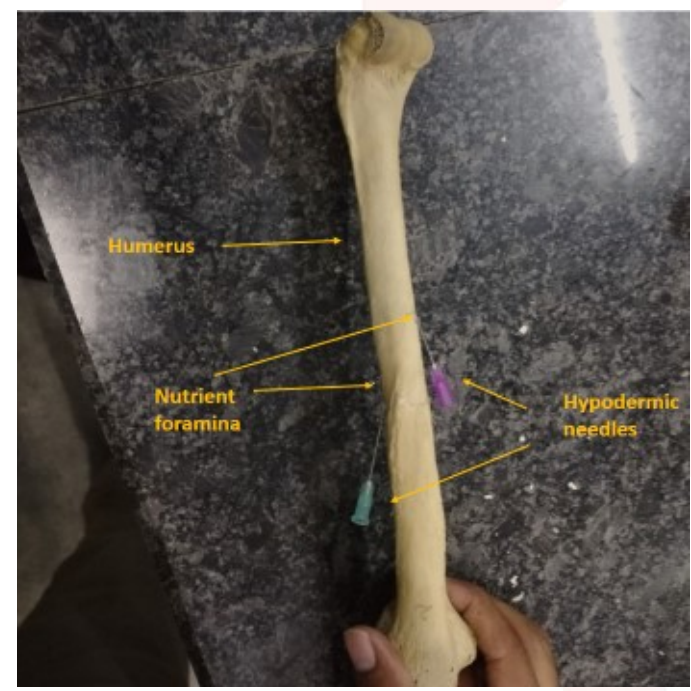

Fig. 3: Photograph of the Humerus showing vertical division of the long axis into 3 zones.
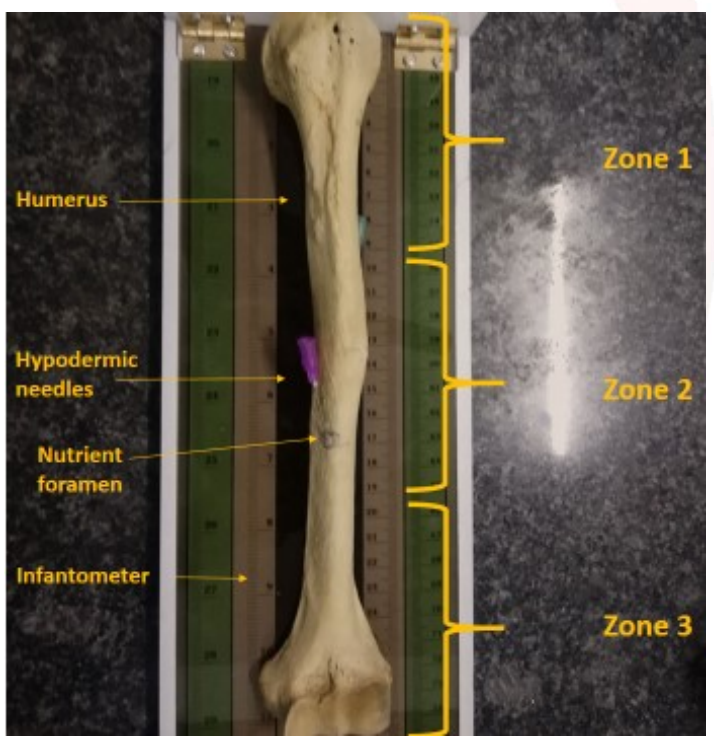

Int J Anat Res 2019, 7(3.1):6700-11.

ISSN 2321-4287

\section{RESULTS}

80 humeri were studied.42 right and 38 left humeri.(Figure 4) .

Fig. 4: Photograph of numerous Humeri which were used for the study.

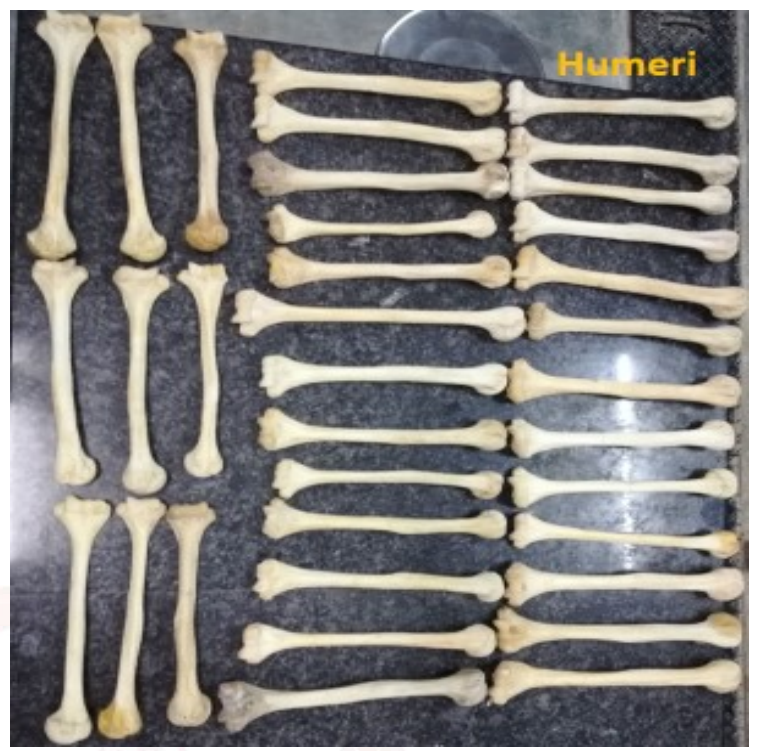

The following observations were made:

Number of foramina: As observed in table 1 and figure 5, 69.04\% of right humeri [29] were having 1 nutrient foramen.(55.26\%) of left humeri (21) were having 1 nutrient foramen, which is the majority. Two nutrient foramina were present in $19.04 \%$ of right humeri (8) and $39.47 \%$ of left humeri (15).Three nutrient foramina were found in $9.25 \%$ of right (4) and $5.26 \%$ of left humeri (2). Absence of nutrient foramen seen in only 1 right humeri with $2.3 \%$.none of the humeri in the sample had 4 or more nutrient foramina.

Thus, in our study $62.50 \%$ (majority) of humeri have 1 nutrient foramen .28.75\% have 2 nutrient foramina $.7 .5 \%$ have three nutrient foramina and $1.25 \%$ with no nutrient foramen and no humeri with 4 or more nutrient foramina.

Location of foramina: Around 99 nutrient foramina were present in 80 humeri which were studied. Location of nutrient foramina on humerus was divided into 3 surfaces and 3 borders. It was found that antero-medial surface (AMS) has $31.25 \%$ [15] of nutrient foramina of right humeri and $54.90 \%$ (28) nutrient foramina of left humeri. Posterior surface (PS) has $12.5 \%$ [6] of nutrient foramina of right humeri and $15.68 \%$ (8) nutrient foramina of left humeri. Antero-lateral surface (ALS) has $2.08 \%$ (1) 
nutrient foramen of right humeri and $1.96 \%$ (1) nutrient foramen of left humeri. Coming to borders, Medial border (MB) has 50\% (24) of nutrient foramina of right humeri and $25.49 \%$ (13) nutrient foramina of left humeri. Anterior border (AB) has $2.08 \%$ (1) nutrient foramen of right humeri and $1.96 \%$ (1) nutrient foramen of left humeri. Lateral border (LB) has $2.08 \%$ (1) nutrient foramen of right humeri and none in left humeri.

Thus, in our study majority (43.43\%) of nutrient foramina were present in AMS and $37.37 \%$ in Medial border (MB) followed by $14.14 \%$ in posterior surface (PS), $2.02 \%$ in both anterolateral surface (ALS) and anterior border (AB). Lastly $1.01 \%$ in lateral border (LB). [Table 2, figure 6]

Vertical position of foramina: As we can see in Table 3 ,Zone 1 has no nutrient foramina in right humeri and $1.96 \%$ (1) in left humeri. Zone 2 has $93.75 \%(45)$ in right humerus and $88.23 \%$ (45) in left humerus. Zone 3 has $6.25 \%(3)$ in right humerus and $9.80 \%(5)$ in left humerus. Zone 3 has $6.25 \%$ (3) in right humeri and 9.80\% (5) in left humeri.

Thus we observed that majority $90.09 \%$ (90) of nutrient foramina were in zone 2 followed by $8.08 \%$ in zone 3 and $1.01 \%$ (1) in zone 1.[fig. 7 ]

Size of foramina: As we can see in Table 4, small gauged [26G] were $16.66 \%$ (8) in right humeri and 31, 37\% (16) in left humeri. Medium gauged [24G] were $39.58 \%$ (19) in right humeri and $29.41 \%(15)$ in left humeri. Large gauged [18-21G] were $43.75 \%(21)$ in right humeri and $39.21 \%(20)$ in left humeri.

Thus, majority $41.41 \%$ (41) of the nutrient foramina were of large gauge [18G-21G], followed by $34.34 \%$ (34) of medium gauge [24G] and $24.24 \%$ (24) of small gauge [18-21G] [figure 8]

Direction of foramina: All the nutrient foramina were directed towards distal end of humerus and obeyed the general rule "to the elbow I go, from the knee I flee" $[5,6,7]$.

sStatistical measurements of Humeri: Mean total length of humeri was observed to be $(300.04 \mathrm{~mm})$ right and $(298.60 \mathrm{~mm})$ left humeri; Mean distance from proximal end of humerus to the nutrient foramen [DNF] was found to be (150.62 mm)right and (157.66 mm) left humeri, FI was found at (50.2\%) right humeri and (52.8\%) left humeri. Total mean length of humeri was found to be $299.5 \mathrm{~mm}$; and mean distance from proximal end of humerus to NF was found to be $154.24 \mathrm{~mm}$ and mean foraminal index [FI] was found to be $51.50 \%$. [Table 5]

Table 1: Number of nutrient foramina in Humeri.

\begin{tabular}{|c|c|c|c|c|c|c|}
\hline \multirow{2}{*}{ Surfaces } & \multicolumn{2}{|c|}{ Right ( NF =48 ) } & \multicolumn{2}{c|}{ Left (NF= 51 ) } & \multicolumn{2}{c|}{ Total ( NF =99) } \\
\cline { 2 - 7 } & Number & $\%$ & Number & $\%$ & Number & $\%$ \\
\hline AMS & 15 & 31.25 & 28 & 54.9 & 43 & 43.43 \\
\hline PS & 6 & 12.5 & 8 & 15.68 & 14 & 14.14 \\
\hline ALS & 1 & 2.08 & 1 & 1.96 & 2 & 2.02 \\
\hline MB & 24 & 50 & 13 & 25.49 & 37 & 37.37 \\
\hline AB & 1 & 2.08 & 1 & 1.96 & 2 & 2.02 \\
\hline LB & 1 & 2.08 & 0 & 0 & 1 & 1.01 \\
\hline TOTAL & 48 & 100 & 51 & 100 & 99 & 100 \\
\hline
\end{tabular}

Fig. 5: Percentage distribution of number of nutrient foramina in Humeri.

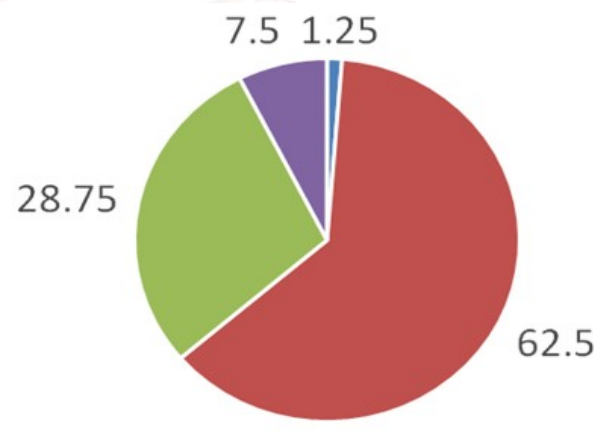

zero $\square$ one $\square$ two $\square$ three

Table 2: Location of nutrient foramina in relation to different surfaces of Humerus.

\begin{tabular}{|c|c|c|c|c|c|c|}
\hline \multirow{2}{*}{ Zones } & \multicolumn{2}{|c|}{ Right (48 NF) } & \multicolumn{2}{c|}{ Left (51 NF) } & \multicolumn{2}{c|}{ Total( 99 NF) } \\
\cline { 2 - 7 } & Number & $\%$ & Number & $\%$ & Number & $\%$ \\
\hline Zone I & 0 & 0 & 1 & 1.96 & 1 & 1.01 \\
\hline Zone II & 45 & 93.75 & 45 & 88.23 & 90 & 90.09 \\
\hline Zone III & 3 & 6.25 & 5 & 9.8 & 8 & 8.08 \\
\hline Total & 48 & 100 & 51 & 100 & 99 & 100 \\
\hline
\end{tabular}

Fig. 6: Location of nutrient foramina on different surfaces of Humerus.

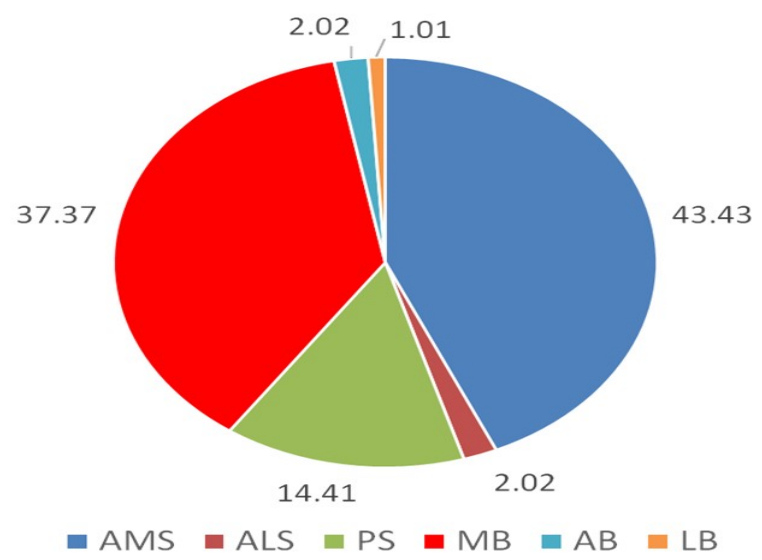


Ruthwik B S, Padmalatha K, Shyam Sunder B V. A STUDY ON NUTRIENT FORAMEN OF HUMERI AND ITS CLINICAL SIGNIFICANCE.

Table 3: Vertical distribution of nutrient foramina with respect to zones in Humerus.

\begin{tabular}{|c|c|c|c|c|c|c|}
\hline \multirow{2}{*}{ Zones } & \multicolumn{2}{|c|}{ Right (48 NF) } & \multicolumn{2}{c|}{ Left (51 NF) } & \multicolumn{2}{c|}{ Total( 99 NF) } \\
\cline { 2 - 7 } & Number & $\%$ & Number & $\%$ & Number & $\%$ \\
\hline Zone I & 0 & 0 & 1 & 1.96 & 1 & 1.01 \\
\hline Zone II & 45 & 93.75 & 45 & 88.23 & 90 & 90.09 \\
\hline Zone III & 3 & 6.25 & 5 & 9.8 & 8 & 8.08 \\
\hline Total & 48 & 100 & 51 & 100 & 99 & 100 \\
\hline
\end{tabular}

Fig. 7: Vertical distribution of nutrient foramina with respect to zones in Humerus (\%).

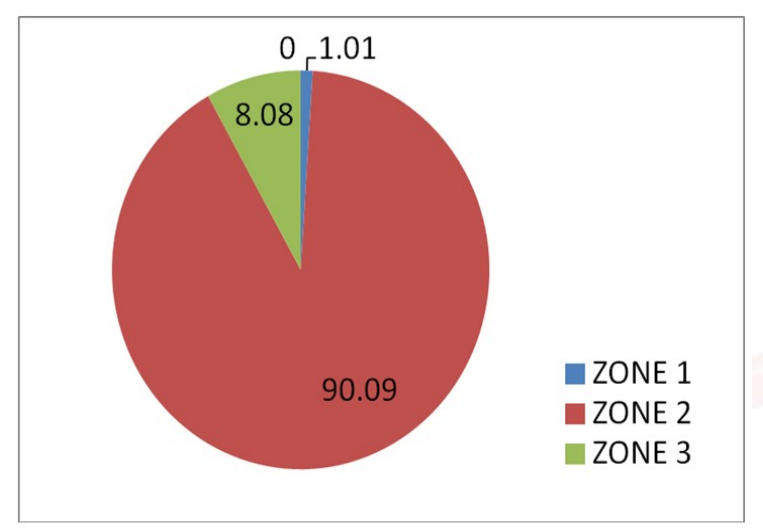

Table 4: Incidence of different sizes of nutrient foramina in Humerus.

\begin{tabular}{|c|c|c|c|c|c|c|}
\hline $\begin{array}{c}\text { Size of nutrient } \\
\text { foramen }\end{array}$ & \multicolumn{2}{|c|}{ Right (48 NF) } & \multicolumn{2}{c|}{ Left (51 NF) } & \multicolumn{2}{c|}{ Total (99) } \\
\hline & Number & $\%$ & Number & $\%$ & Number & $\%$ \\
\hline Small(26 G) & 8 & 16.66 & 16 & 31.37 & 24 & 24.24 \\
\hline Medium (24 G) & 19 & 39.58 & 15 & 29.41 & 34 & 34.34 \\
\hline Large (18-21 G) & 21 & 43.75 & 20 & 39.21 & 41 & 41.41 \\
\hline Total & 48 & 100 & 51 & 100 & 99 & 100 \\
\hline
\end{tabular}

Fig. 8: Incidence of size of nutrient foramen in Humerus (\%).

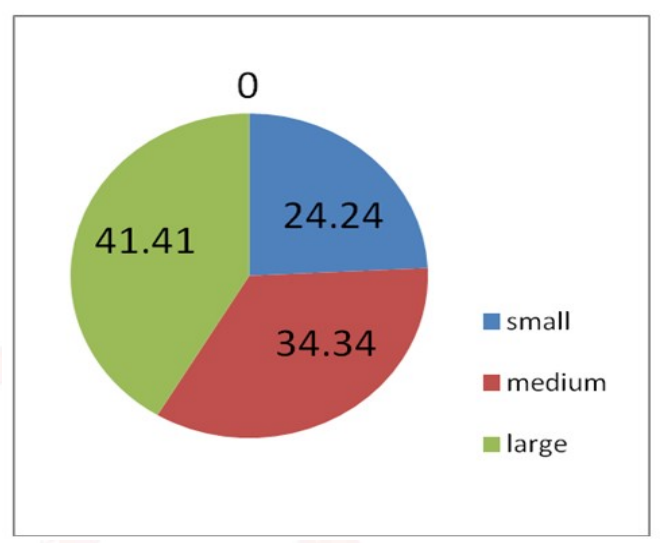

Table 5: Foraminal index and mean length of Humeri.

\begin{tabular}{|c|c|c|c|}
\hline Parameters & Right $(n=48)$ & Left $(n=51)$ & Total $(n=99)$ \\
\hline Mean total length & $300.04 \mathrm{~mm}$ & $298.6 \mathrm{~mm}$ & $299.5 \mathrm{~mm}$ \\
\hline Distance from proximal end to NF & $150.62 \mathrm{~mm}$ & $157.66 \mathrm{~mm}$ & $154.24 \mathrm{~mm}$ \\
\hline Foraminal Index & $50.20 \%$ & $52.80 \%$ & $51.50 \%$ \\
\hline
\end{tabular}

Table 6: Comparison of number of nutrient foramen reported from the previous studies with the present study.

\begin{tabular}{|l|c|c|c|c|c|}
\hline \multicolumn{1}{|c|}{ AUTHORS } & & \multicolumn{3}{c|}{ No. of Foramina } \\
\cline { 2 - 6 } & No. of bones & $\mathbf{0}$ (\%) & $\mathbf{1}$ (\%) & $\mathbf{2}(\%)$ & $\mathbf{3}(\%)$ \\
\hline Carroll (1963) (East Indian and North American Indian population) & 71 & - & 67.6 & 28.2 & 4.2 \\
\hline Mysorekar (1967) (Indian population) & 180 & - & 57.8 & 37.8 & 2.8 \\
\hline Longia et al. (1980) (Indian population) & 200 & 2 & 85 & 13 & - \\
\hline Forriol Campos et al. (1987) (Spanish population) & 36 & - & 75 & 25 & - \\
\hline Kizilkanat et al. (2007) (Turkish population) & 101 & 1.9 & 68.3 & 21.8 & 6.9 \\
\hline Chandrasekaran and Shanthi (2013) (Indian population) & 258 & - & 76.7 & 20.5 & 2.7 \\
\hline Bhojara VS, Kalthur SG, Dsouza AS (2014) (Indian population) & 100 & 3 & 77 & 18 & 2 \\
\hline PRESENT STUDY (INDIAN POPULATION) & $\mathbf{8 0}$ & $\mathbf{1 . 2 5}$ & $\mathbf{6 2 . 5}$ & $\mathbf{2 8 . 7 5}$ & $\mathbf{7 . 5}$ \\
\hline
\end{tabular}

Table 7: Comparison of location of nutrient foramina on different surfaces of Humerus of previous studies with present study.

\begin{tabular}{|l|c|c|c|c|}
\hline \multicolumn{1}{|c|}{ AUTHORS } & $\begin{array}{c}\text { No. of } \\
\text { bones }\end{array}$ & zone 1 \% & zone 2\% & zone $3 \%$ \\
\hline Carroll (1963) (East Indian and North American Indian population) & 71 & 3.1 & 91.7 & 5.2 \\
\hline Mysorekar (1967) (Indian population) & 180 & 1.1 & 95.8 & 3 \\
\hline Longia et al. (1980) (Indian population) & 200 & 3.6 & 90.9 & 5.4 \\
\hline Forriol Campos et al. (1987) (Spanish population) & 36 & - & - & - \\
\hline Kizilkanat et al. (2007) (Turkish population) & 101 & - & - & - \\
\hline Chandrasekaran and Shanthi (2013) (Indian population) & 258 & - & 86.4 & 13.5 \\
\hline Bhojara VS, Kalthur SG, Dsouza AS (2014) (Indian population) & 100 & - & 95.9 & 4.1 \\
\hline PRESENT STUDY (INDIAN POPULATION) & $\mathbf{8 0}$ & $\mathbf{1 . 0 1}$ & $\mathbf{9 0 . 0 9}$ & $\mathbf{8 . 0 8}$ \\
\hline
\end{tabular}


Table 8: Comparative analysis of vertical position of nutrient foramina in Humeri reported from previous studies with present study.

\begin{tabular}{|l|c|c|c|c|c|c|c|}
\hline \multicolumn{1}{|c|}{ AUTHORS } & $\begin{array}{c}\text { No. of } \\
\text { bones }\end{array}$ & AB \% & MB \% & LB \% & AMS \% & ALS \% & PS \% \\
\hline Carroll (1963) (East Indian and North American Indian population) & 71 & 2.1 & 21.6 & 13.4 & 51.5 & - & 11.3 \\
\hline Mysorekar (1967) (Indian population) & 180 & 1.1 & 40 & - & 40 & - & 1.1 \\
\hline Longia et al. (1980) (Indian population) & 200 & 1.8 & - & 1.8 & 82.9 & 0.9 & 9.9 \\
\hline Forriol Campos et al. (1987) (Spanish population) & 36 & - & - & - & 81.8 & 2.3 & 15.9 \\
\hline Kizilkanat et al. (2007) (Turkish population) & 101 & 17.4 & - & 0.7 & 62.3 & 1.5 & 18.1 \\
\hline Chandrasekaran and Shanthi (2013) (Indian population) & 258 & - & - & - & 89.9 & 1.5 & 8.5 \\
\hline Bhojara VS, Kalthur SG, Dsouza AS (2014) (Indian population) & 100 & - & 41.8 & 1.6 & 49.2 & 1.6 & 5.7 \\
\hline PRESENT STUDY (INDIAN POPULATION) & $\mathbf{8 0}$ & $\mathbf{2 . 0 2}$ & $\mathbf{3 7 . 3 7}$ & $\mathbf{1 . 0 1}$ & $\mathbf{4 3 . 4 3}$ & $\mathbf{2 . 0 2}$ & $\mathbf{1 4 . 4 1}$ \\
\hline
\end{tabular}

Table 9: Comparison of size of nutrient foramina reported from the previous studies with the present study.

\begin{tabular}{|c|c|c|c|c|}
\hline \multirow[b]{2}{*}{ AUTHORS } & \multirow{2}{*}{$\begin{array}{l}\text { No. of } \\
\text { bones }\end{array}$} & \multicolumn{3}{|c|}{ Size of the foramina } \\
\hline & & Small (\%) & Medium(\%) & Large (\%) \\
\hline Carroll (1963) (East Indian and North American Indian population) & 71 & 7 & 41 & 52 \\
\hline Mysorekar (1967) (Indian population) & 180 & - & - & - \\
\hline Longia et al. (1980) (Indian population) & 200 & 18 & 80.2 & 1.8 \\
\hline Forriol Campos et al. (1987) (Spanish population) & 36 & - & - & - \\
\hline Kizilkanat et al. (2007) (Turkish population) & 101 & 30.7 & 69.3 & - \\
\hline Chandrasekaran and Shanthi (2013) (Indian population) & 258 & - & - & - \\
\hline Bhojara VS, Kalthur SG, Dsouza AS (2014) (Indian population) & 100 & $\ldots$ & 0.8 & 85.2 \\
\hline PRESENT STUDY (INDIAN POPULATION) & 80 & 24.24 & 34.34 & 41.41 \\
\hline
\end{tabular}

Table 10: Comparative analysis of foraminal index and mean length of Humeri reported from previous study with present study.

\begin{tabular}{|l|c|c|c|c|}
\hline \multicolumn{1}{|c|}{ Authors } & Study population & No. of bones & Mean length (cm) & FI (range) \\
\hline Carroll, 1963 & $\begin{array}{c}\text { East Indian and North American } \\
\text { Indian population }\end{array}$ & 71 & 29.4 & - \\
\hline Mysorekar, 1967 & Indian population & 180 & - & $26.51-74.46$ \\
\hline Forriol Campos et al., 1987 & Spanish population & 36 & - & $47.10-63.70$ \\
\hline Kizilkanat et al., 2007 & Turkish population & 101 & 30.64 & $15.00-69.40$ \\
\hline Pereira et al., 2011 & Southern Brazil & 174 & - & $32.1-68.8$ \\
\hline Bhojara VS, Kalthur SG, Dsouza AS (2014) & Indian population & 100 & 30.7 & $41.11-66.86$ \\
\hline PRESENT STUDY & Indian population & $\mathbf{8 0}$ & $\mathbf{2 9 . 9 5}$ & $\mathbf{3 9 . 3 4 - 8 1 . 0 2}$ \\
\hline
\end{tabular}

\section{DISCUSSION}

In this era due to changes in life style and dependency over machines, injury and fracture of bones are common. For the healing of wound and fractures blood supply plays a vital role[12, 13]. Awareness about the variations in number, location, size and direction of nutrient foramina is important because damage to nutrient artery due to any cause like trauma, road traffic accidents, stripping of bone surface by orthopaedicians for plate insertion in open reduction internal fixation of shaft of humerus etc. will damage nutrient artery and results in inadequate blood supply and it is a well-known fact that one of the causes of delayed union /nonunion of fracture is cutoff of arterial supply [14].
Number of foramina: In our study we found that single nutrient foramen was present in majority of the humeri with $(62.50 \%)$ followed by two NF $(28.75 \%)$ followed by three NF $(7.50 \%)$ and no NF in (1.25\%). Order of incidence is in agreement with all previous studies [2,6,15,18-21]. Study done by Carroll SE [15] (East Indian and North American Indian population), Mysorekar VR [6] (Indian population ), Kizilkanat E et al [2] (Turkish population) and Chandrasekaran and Shanti [18] (Indian population ) have same order of incidence. Study by Longia et al [19] (Indian population) and Forriol campos F et al [20] (Spanish population) did not observe 3 or more NF. No nutrient foramen was found in our study (1.25\%), Longia et al [19] (indian population) (2\%), Kizilkanat $\mathrm{E}$ et al [2] (Turkish 
population ) (1.9\%) and Bhojara VS et al [21] (Indian population) (3\%). Rest other studies $[6,15,18,20]$ did not find any humeri with no NF. We did not find $4 \mathrm{NF}$ in our study but Mysorekar VR [6] (Indian population ), Kizilkanat E et al [2] (Turkish population ) and Mansur DI et al [17] have reported 4 NF.[Table 6]

We can assert that most of the authors have observed that incidence of number of NF in majority of humeri is $1 \mathrm{NF}$ followed by 2 and 3 NF. Veryrarely absent or 4 or more are seen.

Location of foramina: In our study we have observed that majority (43.43\%) of NF are found on Anteromedial surface [AMS] followed by Medial border [MB](37.37\%), Posterior surface[PS] (14.14\%), Anterolateral surface $[A L S]=$ Anterior border (2.02\%) and Lateral border [LB] (1.01\%) and is in accordance with study done by Carroll SE [15] (East Indian and North American Indian population) $[51.5 \%$ on AMS] andBhojara VS et al [21] (Indian population) [ $49.2 \%$ on AMS] .But in study done by Mysorekar VR [6] (Indian population ) AMS = MB with $(40 \%)$ each. Rest other studies have not considered borders separately and they have observed incidence of majority of NF in AMS followed by PS and ALS. [Table 7]

Thus it shows that majority of NF will be on AMS followed by $M B$, $P S, A B, A L S$ and $L B$.

Vertical position of foramina:In our study on Indian population, majority ( $90.09 \%$ ) of NF were found in Zone 2 followed by Zone 3 (8.08\%) and Zone 1 (1.01\%). All the studies from other authors $(2,6,15,18,19,20$, and 21$)$ have agreed and we can conclude that incidence of NF is found more in Zone $3>$ Zone $2>$ Zone 1.[Table 8]

Size of foramina : In our study majority (41.41\%) of NF were of large size [18G-21G] followed by medium size [24G] (34.34\%) and small size[26G] (24.24\%) which is in agreement with study done by Carroll SE [15] (East Indian and North American Indian population) where large size $(52 \%)$ followed by medium size $(41 \%)$ and small size (7\%).Bhojara VS et al [21](Indian population) also observed same pattern with large size $(85.2 \%)$, medium size $(0.8 \%)$ and no small size. Not much studies have been done on size variation of NF. There is a disagreement with study done by Longia et al [19] (Indian population) with medium size (80.2\%), small size (18\%) and large size(1.8\%). Kizilkanat E et al [2]' (Turkish population ) also observed medium size (69.3\%), small size (30.7\%) and no large size. Thus there is too much variations in size of NF in the Indian population itself.[Table 9]

Direction of foramina: In our study we observed that all NF were directed downwards towards the distal end of humerus and obeyed the general rule which states that "to the elbow I go, from the knee I flee" [5-7]. This is in agreement with all other studies $[2,6,15,18-21]$ where it is observed that nutrient foramina is directed towards distal end of humerus. It our study, mean length of humerus was $29.95 \mathrm{~cm}$. and Foraminal Index (FI) ranging from 39.34 to 81.02. When compared to previous studies $[2,6,16,18-21]$ there is not more than $10 \mathrm{~mm}$ variation in length of humerus.In study done by Mysorekar VR [6] (Indian population ) FI ranged from 26.51 to 74.46. Kizilkanat E et al [2](Turkish population) has observed $\mathrm{FI}$ ranging from $15.00-69.40$. Such lower limit could be due to variation in the ethnicity as it was humeri of Turkish population but mean length of humerus was similar to Indian population. [Table 10]

Thus in our study we observed Fl upper limit of 81.02 which was not seen in other previous studies $[2,6,15,18-21]$. There is wide range of variation in $\mathrm{FI}$ when the comparison is made with previous studies[2,6,15,18-21].

\section{CONCLUSION}

This study confirms the reports of the previous studies regarding number, position, vertical distribution and direction of NF. Majority of humeri have single nutrient foramen located on anteromedial surface in zone 2 (middle third) of shaft of humerus and is directed downwards towards distal end of humerus obeying the general law "to the elbow I go, from the knee I flee" $[5,6,7]$. There is much variation in size of nutrient foramina when compared to previous studies and we observed majority to be large sized (18G) .more studies are required to confirm or refute the finding.

In modern era due to industrialization and changes in life style and dependency over machines, injury and fracture of bones are common. For the healing of wound and fractures, 
blood supply play a major role [12,13].

Awareness about the variations in number, location, size and direction of nutrient foramina is important because damage to nutrient artery due to any cause like trauma, road traffic accidents, stripping of bone surface by Orthopaedicians for plate insertion in open reduction internal fixation of comminuted fractures of shaft of humerus etc. will cause inadequate blood supply. It is a well-known fact that one of the causes of delayed union or nonunion of fracture is lack of arterial supply [14]. This knowledge helps vascular surgeons and bone transplant surgeons to avoid ischemia of the graft during arm transplant surgeries in unfortunate victims of accidents/attacks thus providing adequate vascularity and increasing the chances of successful transplantation.

\section{ABBREVIATIONS}

NF - Nutrient foramen

$\mathrm{FI}$ - Foraminal index

AMS - Antero-medial surface

MB - Medial border

G - Gauge

DNF - Distance from proximal end of bone to nutrient foramen

TL - Total length

PS - Posterior surface

ALS - Antero-lateral surface

$A B$ - Anterior border

LB - Lateral border

\section{ACKNOWLEDGEMENTS}

The authors are thankful to students of ESIC medical college \& PGIMSR, Bangalore and Dr. Biswabina Ray, Professor \& HOD, Department of Anatomy for encouraging and supporting us to carry out this study.

\section{Conflicts of Interests: None}

\section{REFERENCES}

[1]. Branemark PI. Vital microscopy of bone marrow in rabbit.Scand J Clin Lab Invest 1959;11 Supp 38:182.

[2]. Kizilkanat, E.; Boyan, N.; Ozsahin, E. T.; Soames, R. \& Oguz, O. Location, number and clinical significance of nutrient foramina in human long bones. Ann. Anat., 2007; 189:87-95.

[3]. Malukar O, Joshi H. Diaphysial Nutrient Foramina in Long Bones And Miniature Long Bones, NJIRM;2011;2(2):23-26.
[4]. Standring S. Functional anatomy of the musculoskeletal system. Gray's Anatomy. The Anatomical basis of clinical practice. 40th edition. London:Churchill Livingston Elsevier, 2008;p 85-91

[5]. Bharathi A, Janaki V, Gouri TLS, Archana. Morphometric variations of nutrient foramen in adult human humerus in Telangana region. Journal of Dental and Medical sciences 2016; 15(4):43-6.

[6]. Mysorekar VR, Diaphysial nutrient foramina in human long bones, J Anat, 1967, 101(Pt4):813-822.

[7]. Taylor GI, Fibular transplantation. In: Serafin D, Bunke HJ (eds), Microsurgical composite tissue transplantation, C.V. Mosby Co., St. Louis,1979;418423.

[8]. Singh V. Skeleton. In: Textbook of Anatomy. $1^{\text {st }}$ edition. New Delhi: Elsevier, 2008;80.

[9]. Richard L. Drake, Wayne Vogl, Adam W.M. Mitchell, Henry Gray's editors. Gray's Anatomy. Churchill Livingstone/ Elsevier,2005; 822-826.

[10]. Henderson RG. The position of the nutrient foramen in growing tibia \& femur of the rat. Journal of Anat. 1978;125(3):593-599

[11]. Joshi H, Dosh B, Malukar O. A study of the nutrient foramina of the humeral diaphysis. Natl J Integr Res Med 2011;2:15-7.

[12]. Coolbough CC. Effect of reduced blood supply on bones. American Journal of physiology. 1952;169:26-33.

[13]. Laing PG. The arterial supply of adult humerus. Journal of bone and joint surgery 1956;A-38:11051116.

[14]. Sharma M, Prashar R, Sharma T, Wadhwa A. Morphological Variations of Nutrient Foramina in upper limb long bones. Int J Med and Dent Sci. 2013;2(2):177

[15]. Carroll SE. A study of the nutrient foramina of the humeral diaphysis. J Bone Joint Surg Br 1963;45B:176-81.

[16]. Hughes $H$. The factors determining the direction of the canal for the nutrient artery in the long bones of mammals and birds. Acta Anat (Basel) 1952;15:26180.

[17]. Mansur DI, Manadhar P, Haque MK, Mehta DK, Duwal S, Timalsina B. A Study on Variations of Nutrient Foramen of Humerus with its Clinical Implications.Kathmandu Univ Med J 2016;53(1):7883.

[18]. Chandrasekaran S, Shanthi KC. A study on the nutrient foramina of adult humerii. J Clin Diagn Res 2013;7:975-7.

[19]. Longia GS, Ajmani ML, Saxena SK, Thomas RJ. Study of diaphyseal nutrient foramina in human long bones. Acta Anat (Basel) 1980;107:399-406.

[20]. Forriol Campos F, Gomez Pellico L, Gianonatti Alias M, Fernandez-Valencia R. A study of the nutrient foramina inhuman long bones. Surg Radiol Anat 1987;9:251-5.

[21].Bhojaraja VS, Kalthur SG, Dsouza AS. Anatomical study of diaphyseal nutrient foramina in human adult humerus. Arch Med Health Sci 2014;2:165-9. 